\title{
Visual deficits in children born at less than 32 weeks' gestation with and without major ocular pathology and cerebral damage
}

\author{
Heather J Dowdeswell, Alan M Slater, John Broomhall, John Tripp
}

\begin{abstract}
Aims-A study was carried out to compare the visual abilities of prematurely born children with those of matched full term controls.

Methods-The vision of 68 children born at less than 32 weeks' gestation and aged between 5 and $71 / 2$ years at the time of testing was compared with that of a control group of children born at full term, and matched for sex and age from due date.

Results-The premature children had significantly poorer distance and near visual acuity, contrast sensitivity and stereopsis, and a high incidence of colour vision defects (predominantly tritan type). These differences were associated with the high incidence of ocular pathology experienced by $31(45 \%)$ of the premature children compared with only nine $(13 \%)$ of the controls. When excluding children with ocular and cerebral pathology, 32 matched pairs of premature and control children remained. The 32 premature children did not differ from their controls in terms of distance and near acuities or stereopsis, but they did have significantly poor contrast sensitivity in both their 'best' and 'worst' eyes. None of the 32 control children had colour vision defects, compared with seven of the matched premature children.

Conclusion-This adds support to previous speculation that the preterm eye is at risk of subtle visual impairment independent of the occurrence of refractive error, manifest squint, disorders of the fundus and media, and cerebral damage.

(Br f Ophthalmol 1995; 79: 447-452)
\end{abstract}

Department of Psychology, University of Exeter, Exeter EX4 4QG

H J Dowdeswell

A M Slater

Special Care Baby Unit, Royal Devon and Exeter Hospital, Heavitree, Gladstone Road, Exeter EX1 2ED J Broomhall

Department of Child Health, Church Lane, Heavitree, Exeter

EX2 5SQ

J Tripp

Correspondence to:

Dr $\mathrm{H}$ Dowdeswell.

Accepted for publication

9 December 1994 poorer than that of control children born at full term. ${ }^{11} 12$ Children born at less than 32 weeks and/or with a birth weight of less than $1500 \mathrm{~g}$ have also been reported to have an increased incidence of colour vision impairments unrelated to major ocular pathology or cerebral such subtle deficits is speculative. Abramov et al ${ }^{14}$ studied the visual performance of 7 year olds who had been born at unspecified gestational ages and undergone neonatal intensive care. They detected subtle deficits related to cone functions - poorer acuity, contrast sensitivity function, and colour vision - which were not found in 'non-risk' controls. These authors suggest that the deficits could be due both to the high levels of ambient illumination of the neonatal unit and to stray light from phototherapy causing damage to cone photoreceptors. Moseley and Fielder ${ }^{15} 16$ and Fielder et $a l^{910}$ have discussed the possibility that light may be toxic to the preterm eye and not only contribute to the development of well documented defects such as retinopathy, but also cause photoreceptor damage which could lead to more subtle visual impairments.

This study compares the visual abilities of prematurely born children (less than 32 weeks' gestation) with that of matched full term controls, and is concerned with two issues: (1) a comparison of ocular and cerebral pathology between the two groups, and the relation of pathology to visual problems, and (2) whether subtle visual impairments may occur independently of ocular and cerebral pathology such as cicatricial retinopathy, optic nerve abnormalities, refractive error, manifest squint, and cerebral damage.

We had the following aims:

(1) To determine the incidence of ocular defects and cerebral damage in a cohort of children born at less than 32 weeks' gestation and aged between 5 and $71 / 2$ years at the time of testing.

(2) To compare the visual acuity, contrast sensitivity, stereopsis, and colour vision of these premature children with a group of children born at full term and matched for sex and age from due date.

(3) To repeat these comparisons between prematures and controls once children with ocular pathology (refractive error, manifest squint, abnormalities of the optic nerve head, cicatricial retinopathy), or cerebral damage (cerebral palsy, mental retardation, and minimal brain damage) had been excluded, to determine whether any differences in visual acuity, contrast sensitivity, stereopsis, and colour vision remain. damage $^{13}$ (unpublished findings). The cause of

\section{Method}

PRETERM SUBJECTS

The preterm group consisted of 68 children 
Table 1 Premature babies born at less than 32 weeks' gestation and admitted between fanuary 1984 and May 1986

\begin{tabular}{lcccc}
\hline & & & \multicolumn{2}{c}{ Survivors tested } \\
\cline { 3 - 5 } $\begin{array}{l}\text { Gestational } \\
\text { age (weeks) }\end{array}$ & $\begin{array}{l}\text { Number } \\
\text { admitted }\end{array}$ & $\begin{array}{l}\text { Number } \\
\text { surviving }\end{array}$ & Number & $\begin{array}{l}\text { Birth weights } \\
\text { (range (g)) }\end{array}$ \\
\hline 24 & 5 & 0 & & \\
25 & 4 & $2(50 \%)$ & $2(100 \%)$ & $810-825$ \\
26 & 14 & $6(43 \%)$ & $6(100 \%)$ & $770-1090$ \\
27 & 10 & $7(70 \%)$ & $5(71 \%)$ & $900-1040$ \\
28 & 13 & $10(85 \%)$ & $9(90 \%)$ & $970-1550$ \\
29 & 19 & $13(79 \%)$ & $11(85 \%)$ & $885-1620$ \\
30 & 21 & $19(91 \%)$ & $13(68 \%)$ & $730-1730$ \\
31 & 33 & $31(94 \%)$ & $22(71 \%)$ & $1146-2010$ \\
Total & 119 & $88(74 \%)$ & $68(77 \%)$ & \\
\hline
\end{tabular}

born before 32 weeks' gestation and admitted to the neonatal intensive care unit at the Royal Devon and Exeter Hospital (Heavitree), between 1 January 1984 and 31 May 1985. During this period 119 babies born before 32 weeks' gestation were admitted to the unit. Thirty one $(26 \%)$ died ( 28 on the unit, three after discharge), leaving 88 survivors aged between 5 and $71 / 2$ years at the time of this study. Sixty eight $(77 \%)$ of the 88 survivors attended for visual testing. The gestational ages and range of birth weights of the survivors tested are given in Table 1.

\section{CONTROL SUBJECTS}

The controls consisted of a matched group of 68 children who had been born at full term, and all but three had been born at the same hospital. Each control child was selected to provide a match for a premature child in terms of sex and age (plus or minus 1 week) from due date at the time of testing. The mean age (from due date) of both controls and prematures was 6 years $2 \frac{1}{2}$ months, range 5 years 2 months to 7 years 6 months. The control children did not differ significantly from the premature children in range of social class, employment status of father, or marital status of mother at the time of the child's birth, but they were not individually matched for these variables. There was one difference between the two groups in that the mean age of the mother on the child's due date was significantly higher for the control group (29.6 years) than for the premature group (26.9 years) $\left(\mathrm{t}_{(132)}=3.37, \mathrm{p}=0.001\right)$.

\section{RECRUITMENT OF PREMATURE SUBJECTS}

Eighty one of the 88 surviving premature children were traced via their general practitioners and relevant family health services authorities. The other seven could not be traced. The 81 premature children and their parents or guardians were invited by letter to attend a follow up clinic at the West of England Eye Infirmary, Exeter, in September or October 1991. Thirteen children were unable to attend (nine lived outside Devon and the parents of four of the 72 children living in Devon refused to attend), but all of their parents or guardians returned questionnaires giving details of any ophthalmic or medical problems that the child had experienced. The results of the questionnaire are not given here, but they indicated that the untested children had a comparable incidence of gestational age, physical, mental, and ophthalmic handicap with that of the 68 premature children tested, and so the 68 tested were taken to be representative of the overall group.

RECRUITMENT OF CONTROL SUBJECTS

Once testing of the premature children was completed, the 68 control children were recruited by letter from a local school. In order to achieve appropriate matching with the premature children for age (from due date at time of testing) and sex, a larger sample was recruited until precise matches were made.

\section{OCULAR ASSESSMENT}

The ocular assessment was in two parts: (1) tests of visual performance, which consisted of measures of visual acuity and contrast sensitivity measurements for each eye, stereopsis, and colour vision; (2) tests of ocular pathology, which included an assessment of ocular motility, and refraction, and ophthalmic examination. The tests of visual performance and the assessment of ocular motility were carried out by the same orthoptist. Fuller details of the ocular assessment are given below.

\section{TESTS OF VISUAL PERFORMANCE}

\section{Visual acuity}

Visual acuity was measured at 6 metres and 0.3 of a metre using $\log M A R$ charts to facilitate accurate measurement. These charts, originally described by Bailey and Lovie ${ }^{17}$ have a logarithmic scaling of letter size, with five letters per line with similar logarithmic spacing between both letters and lines. Equivalent Snellen line sizes were $6 / 3$ to $6 / 60$. The logMAR charts were used in preference to Snellen charts (in which the number of letters per line increases as the letter size decreases) because they allow for accurate recording of acuities where only part of a line is read. ${ }^{18}$ The acuities obtained using the $\log M A R$ chart are often poorer than those obtained using a standard Snellen chart. This is because the logMAR charts are sensitive to 'crowding' effects which lower acuity - an effect that the Snellen charts are unable to assess. ${ }^{18}$

\section{Contrast sensitivity}

Contrast sensitivity was measured using the Pelli-Robson chart. ${ }^{1920}$ This chart, viewed at a distance of 1 metre, consists of 16 three letter triplets of logarithmically decreasing contrast (log sensitivity range $0 \cdot 00$ to $2 \cdot 25$ ). All letters are $49 \mathrm{~mm}$ in height. The chart's designers claim that this test provides an indication of contrast sensitivity in the low to medium spatial frequency range and that it is insensitive to refractive error. 


\section{Stereopsis}

Stereopsis was assessed using the TNO random dot test. A number of premature children with cerebral damage found this difficult to understand and for them the Frisby and Lang tests were used instead.

\section{Colour vision}

Colour vision was assessed using the Farnsworth D15 saturated colour vision test, the results being analysed by using a computer program devised by Vingrys and King-Smith. ${ }^{21}$ An adequate photopic level of illumination was ensured.

\section{TESTS OF OCULAR PATHOLOGY}

\section{Ocular motility}

Ocular motility was assessed by testing monocular rotations (adduction, supraduction, infraduction, intorsion, and extorsion) and the six binocular cardinal directions of gaze, as well as by testing convergence and carrying out cover tests for near and distance fixation to detect manifest and latent squints. Any failure of monocular or binocular motility was recorded as a disorder of ocular motility and did not necessarily predict presence of a squint being detected by the cover tests. Convergence was measured by slowly bringing a small object toward the bridge of the nose and asking the child to try and stop it from 'going double' for as long as possible. The distance from the bridge of the nose at which the eyes 'broke' (that is, the non-dominant eye swung laterally) was noted and convergence was defined as poor if this distance was $7 \mathrm{~cm}$ or more.

\section{Refraction}

Refraction following cycloplegia and ophthalmoscopic examination of the fundus and media

Table 2 Visual performance - overall findings

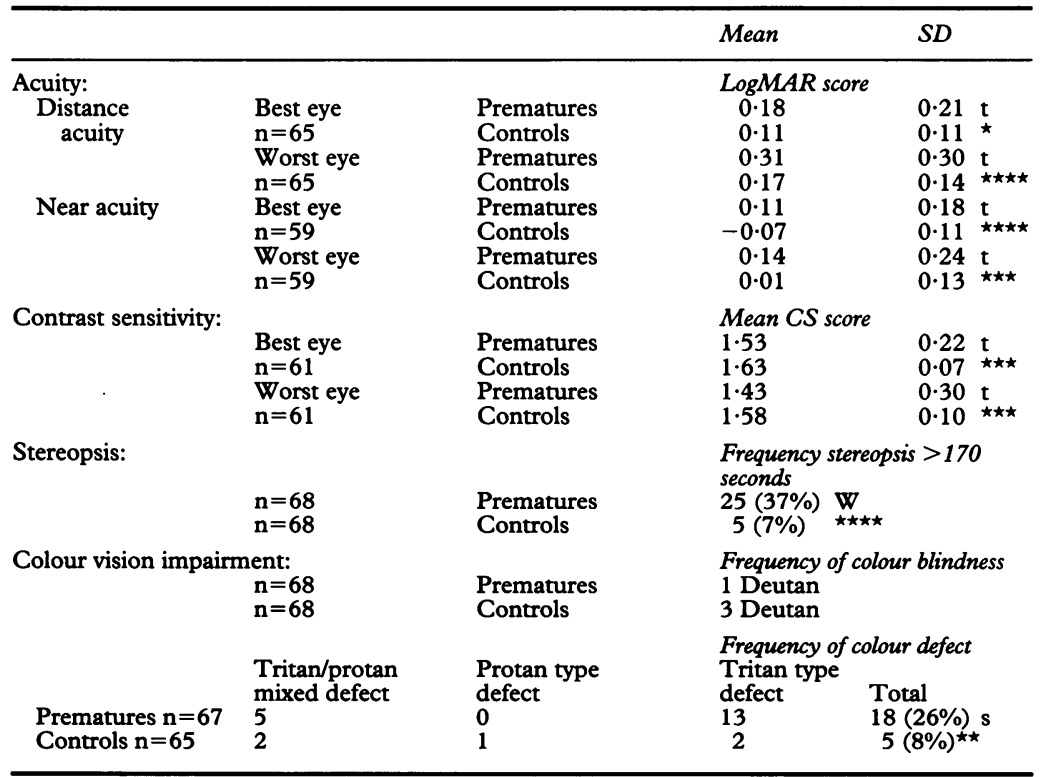

$\mathrm{n}=$ number of subjects; $\mathrm{t}=$ paired $t$ test; $\mathrm{W}=\mathrm{W}$ ilcoxon signed rank test; $\mathrm{s}=$ sign test. ${ }^{\star} \mathrm{p}<0.05,{ }^{\star \star} \mathrm{p}<0.01,{ }^{\star \star \star} \mathrm{p}<0.001,{ }^{\star \star \star \star} \mathrm{p}<0.0001$. were carried out for all children with visual acuity poorer than $0.04 \log$ MAR in one or both eyes. These children received this assessment (which was carried out by a total of 10 opticians and seven ophthalmologists) within 6 months of the visual performance testing.

\section{LOCATION}

The orthoptist assessed the prematurely born children in the outpatient department at the West of England Eye Infirmary, and the control children in a quiet room at their school. The same equipment was used for both groups of children and the tests were carried out in the same order (the order given above) for each child. Normal photopic luminance levels were used throughout.

\section{DETAILS OF DEVELOPMENT AND OPHTHALMIC} CARE

For all premature children and all but three of the controls details of their neonatal history and subsequent medical and ophthalmic care were extracted from hospital and opticians' notes. Extensive details were recorded, including gestational age and how this was assessed (this required examination of both child's and mother's hospital notes), bearing in mind that under 28 weeks estimation can be rather unreliable. Other details recorded were birth weight (with percentile birth weight being calculated according to gestational age and used to give an index of intrauterine growth retardation), Apgar scores, number of days on oxygen therapy, number of days ventilated, presence of jaundice, and maximum bilirubin level, number of days phototherapy given, and length of stay on the neonatal unit. Records of cerebral ultrasound scanning and ophthalmoscopic examination screening for retinopathy of prematurity (both of which had been carried out at some stage on all the prematures) were noted as were the timing and results of developmental assessments in the neonatal unit and subsequent outpatient clinics (neurodevelopmental assessments had been carried out for all prematures while in the neonatal unit and at least one follow up clinic). Any indication that a premature child had cerebral damage or eye disease was discussed with the parents at the follow up interview and the current clinicians involved contacted to ensure that our records were accurate.

The parents of the control children returned a questionnaire which inquired about eye problems only, it having already been established via hospital notes and the school that none of these children had experienced significant developmental delay.

\section{Results}

VISUAL PERFORMANCE

The visual performance of the 68 premature children was significantly worse than that of their controls on five measures; distance acuity (at 6 metres), near acuity (at 0.3 of a 
Table 3 Ocular pathology - overall findings

\begin{tabular}{llcl}
\hline & $\begin{array}{l}\text { Children } \\
(n=68)\end{array}$ & $\begin{array}{c}\text { Frequency } \\
\text { of problem }\end{array}$ & \\
& Prematures & $28(41 \%)$ & \\
Refráctive error & Controls & $9(13 \%)$ & $\star \star \star$ \\
& Prematures & $12(18 \%)$ & \\
Extraocular muscle & Controls & $3(4 \%)$ & $\star$ \\
motility disorder & Prematures & $13(19 \%)$ & \\
Manifest squint & Controls & 0 & $\star \star \star$ \\
Latent squint & Prematures & $10(15 \%)$ & \\
& Controls & $5(7 \%)$ & NS \\
Poor convergence & Prematures & $13(13 \%)$ & \\
& Controls & $10(15 \%)$ & NS \\
Fundus and media & Prematures & $4(6 \%)$ & \\
abnormality & & $(2$ optic atrophy, \\
& & 1 enlarged discs, \\
& & 1 cicatricial ROP $)$ \\
& & 0 & NS \\
\hline
\end{tabular}

Sign test.

$\mathrm{NS}=$ not significant. ${ }^{\star} \mathrm{p}<0.05,{ }^{\star \star} \mathrm{p}<0.01,{ }^{\star \star \star} \mathrm{p}<0.001$

metre), contrast sensitivity, stereopsis, and colour vision. For each of the first three measures, scores were obtained for each eye separately and so the results were analysed in terms of the 'best' and 'worst' eye scores. Mean scores, ranges, and the results of statistical analyses are detailed in Table 2 .

\section{ACUITY}

The premature children's best and worst eyes had significantly poorer acuities than the control children's both for distance and near acuity. Five premature children were unable to see the largest letters on the top line of the distance logMAR chart with one or both eyes, and two premature children were unable to see the largest letters on the top line of the near logMAR chart with one or both eyes. Accurate $\log$ MAR scores are not available for these children but for the sake of statistical calculations they were given a score of $1 \cdot 10$, equivalent to being able to see what would have been bigger letters on the 'line above', almost certainly an overestimate of visual ability given comparison with hospital records of acuity.

\section{CONTRAST SENSITIVITY}

The contrast sensitivity scores for the premature children's best and worst eyes were significantly poorer than the control children's. For the best eyes the premature children's scores ranged from 0.45 to 1.80 , whereas the control children's ranged from 1.35 to $1 \cdot 80$. For the worst eyes the premature children's scores ranged from 0.15 to 1.65 whereas the control children's ranged from 1.35 to 1.65 .

\section{STEREOPSIS}

Twenty five of the premature children, compared with only five of the controls, had stereopsis poorer than 170 seconds. Thirteen

Table 4 Breakdown of refractive errors

\begin{tabular}{llll}
\hline & Controls & Prematures & Sign test \\
\hline No refractive error & $59(87 \%)$ & $40(59 \%)$ & $\mathrm{p}<0.001$ \\
Myopia $>1$ D one or both eyes with or without astigmatism & $3(4 \%)$ & $14(20 \%)$ & $\mathrm{p}<0.005$ \\
Hypermetropia $>1$ D one or both eyes with or without & $4(6 \%)$ & $6(9 \%)$ & NS \\
$\begin{array}{l}\text { astigmatism } \\
\text { Astigmatism only }>1 \text { D one or both eyes }\end{array}$ & $2(3 \%)$ & $8(12 \%)$ & NS \\
\hline
\end{tabular}

of the prematures had no stereoscopic vision compared with none of the controls.

\section{COLOUR VISION}

Colour vision blindness and colour vision defects were detected by computer analysis of the order in which each child had placed the 15 colour discs. Three measures of error were recorded: (1) the confusion index gave an indication of the amount of deviation from the correct order; (2) the selectivity index, which was high if mistakes were made along a constant colour confusion axis (for example, selectively confusing violet/blues with greenish yellows), but low if mistakes were random (as a result of not understanding the task adequately or making deliberate errors (two children were uncooperative and arranged the discs randomly); (3) the angle of confusion gave an indication of whether colour blindness of a protan, deutan, or tritan type was present. Colour blindness was identified by high confusion and selectivity indices, and a specific angle of confusion.

One of the premature boys and three of the control boys had deutan colour blindness. This was not unexpected since the incidence of deutan colour blindness is $8 \%$ in the male population. ${ }^{22}$ The colour vision results for the 132 children without colour blindness were analysed for the presence of colour vision defects in which confusions between colours were made such that errors were repeatedly made in a selective way, but not as severely as in colour blindness. Children with colour vision defects had high confusion and selectivity indices but angles of confusion which were outside the ranges found in colour blindness. The type of defect was established by visually assessing the D15 charts. Thus the term colour vision defect is used here to mean that a child selectively and consistently confuses certain colours along either the protan (red-blue/green), deutan (green-red/purple), or tritan (violet-greenish/yellow) axes, but not to such a degree that colour blindness is present. The incidence of colour defects and colour blindness is shown in Table 2 .

\section{OCULAR PATHOLOGY}

The poor visual performance of the premature children was associated with their higher incidence (when compared with the control group) of ocular pathology, in the forms of refractive error, disorder of extraocular muscle motility, manifest squint, and abnormalities of the fundus and media (see Table 3). In 10 of the premature children previously undiagnosed poor acuity was detected - three of the premature children were referred to an optician and had refractive errors and seven were referred to an ophthalmologist and had more severe refractive errors and squints (five latent, two manifest). Three of the control children required new referrals to be made to an optician for poor acuity and all required correction of refractive errors. No undetected abnormalities of the fundus or media were 
Table 5 Visual performance of 32 matched pairs of controls and prematures without ocular or cerebral pathology

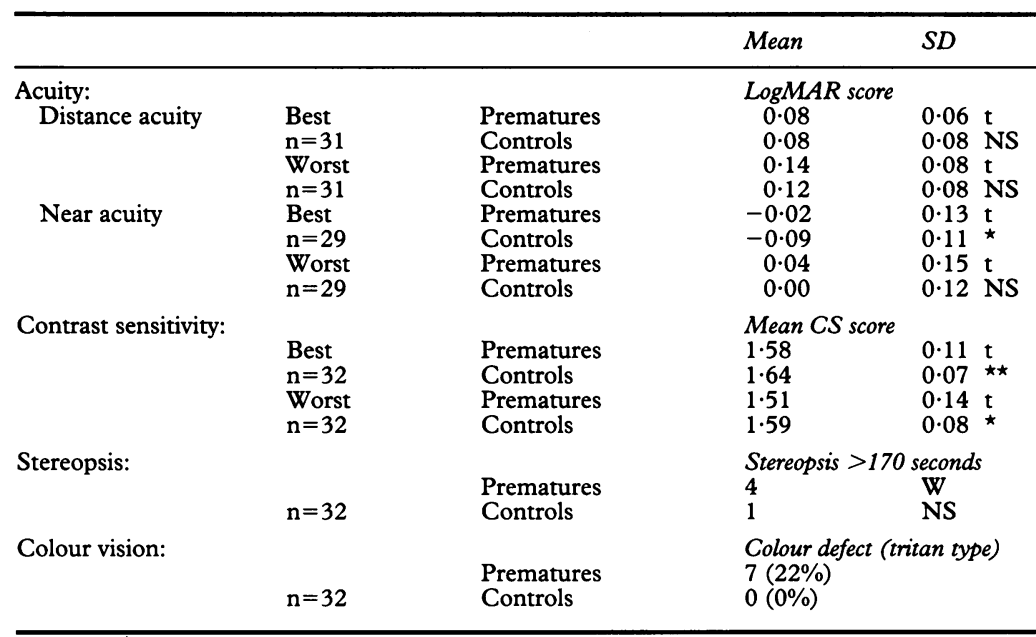

$\mathrm{n}=$ number of matched pairs; $\mathrm{t}=$ paired $t$ test; $\mathrm{W}=\mathrm{W}$ ilcoxon signed rank test; $\mathrm{NS}=$ not significant. ${ }^{\star} \mathrm{p}<0.05,{ }^{\star \star} \mathrm{p}<0.01,{ }^{\star \star \star} \mathrm{p}<0.001,{ }^{\star \star \star \star} \mathrm{p}<0.0001$.

found and so the neonatal checks and outpatient follow ups had been sufficient to pick up the one premature child affected by retinopathy of prematurity and the three premature children with abnormalities of the optic disc. A comparison of the premature and control children's ocular problems is given in Table 3. A breakdown of the refractive findings is given in Table 4, which gives the frequencies of myopia, hypermetropia, and astigmatism, there being a significantly higher incidence of myopia in the premature children. Eight of the 14 premature children with myopia had a manifest squint.

\section{CEREBRAL PATHOLOGY}

Five $(7 \cdot 4 \%)$ of the premature children suffered with cerebral palsy with either mild or moderate mental retardation. One premature child had mild mental retardation without physical handicap, and three premature children had been diagnosed as having minimal brain damage. This gives a total of nine $(13.3 \%)$ with evidence of cerebral damage and eight of these children had ocular pathology (one with manifest squint alone, four with refractive errors alone, one with refractive error and manifest squint, two with refractive errors and optic nerve head abnormalities).

\section{VISUAL IMPAIRMENT IN PREMATURES WITHOUT} OCULAR OR CEREBRAL PATHOLOGY

When premature children with refractive error, manifest squint, optic nerve head abnormalities, cicatricial retinopathy, cerebral palsy, mental retardation, or minimal brain damage were excluded, this left 36 matched pairs. However, four of the controls had refractive errors, so they, too, along with their matching prematures, were excluded from the analysis reported in this section. There were thus 32 matched pairs without ocular or cerebral pathology.

The mean distance and near visual acuities of the 32 premature children remained slightly poorer than those of the controls, but these differences were no longer significant (using the paired $t$ test). Stereopsis was also poorer for the premature children, but again did not reach an acceptable significance level (using the Wilcoxon signed rank test). However, the premature children's contrast sensitivity did remain significantly poorer. For the best eyes the premature children's scores ranged from 1.35 to 1.80 , whereas the control children's ranged from $1 \cdot 50$ to $1 \cdot 80$. For the worst eyes the premature children's scores ranged from 1.05 to 1.65 whereas the control children's ranged from $1 \cdot 35$ to $1 \cdot 65$. Seven of the premature children had a tritan colour vision defect compared with none of the controls. The findings from this analysis are given in Table 5.

RELATION BETWEEN VISUAL OUTCOME, FAMILY HISTORY OF EYE DISEASE, AND NEONATAL FACTORS

No significant link was found between visual outcome and family history of eye disease or neonatal factors such as degree of prematurity, percentile birth weight, 5 minute Apgar score, number of days on oxygen therapy, number of days ventilated, highest bilirubin level, number of days phototherapy given, and length of stay on neonatal unit. These negative findings are difficult to interpret since this study was retrospective and so the neonatal data used were rather crude, and also the number of subjects rather small.

\section{Discussion}

This study found that children who had been born at less than 32 weeks' gestation had significantly poorer acuity, stereopsis, contrast sensitivity, and colour vision than age and sex-matched controls born at full term. The differences in acuity and stereopsis were associated with the higher incidence of ocular pathology (namely, refractive error, manifest squint, cicatricial retinopathy, and optic nerve head abnormalities) and cerebral pathology experienced by the premature children. Those premature children without these pathologies did not differ from the control children in acuity or stereopsis, in contrast with the suggestion by Fledelius ${ }^{11}$ and Sebris et al ${ }^{12}$ that premature children without ocular or cerebral pathologies still had poorer acuity than controls. However, in this study premature children without such pathologies still had poorer contrast sensitivity and a higher incidence of colour vision defects compared with their controls. This suggests that reduced contrast sensitivity and colour vision defects occur in premature children independently of obvious ocular pathologies. This lends support to the hypothesis that the premature visual system may be at risk of subtle damage, as suggested by Abramov et al. ${ }^{14}$

The colour vision defects experienced by the premature children were predominantly of the tritan type, which suggests a defect of the blue cones. Previous workers have suggested that the preterm eye is at risk of receiving high doses of light predominant in the 'blue' 
wavelengths absorbed by the blue cones, and that the long term exposure may destroy cones such that their numbers become permanently depleted. ${ }^{1415}$ Poor contrast sensitivity in the presence of normal acuity and absence of other pathology could also be explained by reduced numbers of cones. Damage to the retina by light has also been implicated in the pathogenesis of retinopathy of prematurity.

This study represents the first detailed assessment of the visual performance of a cohort of children born at less than 32 weeks' gestation using comparison with age and sex-matched control children born at full term. Premature children who escape cerebral pathology and ocular pathology in the form of refractive error, manifest squint, cicatricial retinopathy, and optic nerve head abnormalities appear to have normal acuities and stereopsis. However, a significant number of these premature children with 'normal vision' appear to have subtle visual impairment in the form of reduced contrast sensitivity and colour vision defects (predominantly tritan type). No link was found between visual outcome and family history of eye disease, or neonatal factors such as degree of prematurity, percentile birth weight, 5 minute Apgar score, number of days on oxygen therapy, number of days ventilated, highest bilirubin level, number of days phototherapy given, and length of stay on neonatal unit. Further, prospective studies are needed to investigate the relation between visual outcome and neonatal factors.

The authors are grateful to the following colleagues for their support and assistance: Miss Erika Holden (West of England Eye Infirmary), for carrying out the tests of visual performance on all the children; Mr Stuart Mitchell (West of England Eye Infirmary) for analysing the results of the colour vision tests; D Clive Lawrence (Department of Mathematical Research and Operational Statistics, Exeter University) for carrying out th statistical analyses. We would also like to thank Dr Merrick Moseley, Dr Steve Scotcher, and two anonymous reviewers for their critical reading of the manuscript.

This study was supported by a grant from the Northcott This study was supported
Devon Medical Foundation.

1 Keith CG, Kitchen WH. Ocular morbidity in infants of very low birthweight. Br f Ophthalmol 1983; 67: 302-5.
2 Gallo JE, Lennerstrand G. A population-based study of ocular abnormalities in premature children aged 5 to 10 years. Am f Ophthalmol 1991; 111: 539-47.

3 Saigal S, Rosenbaum P, Stoskopf B, Sinclair JC. Outcome of infants 501 to $1000 \mathrm{~g}$ birth weight delivered to residents of the McMaster Health Region. $\mathcal{F}$ Pediatr 1984; 105f: 969-76.

4 Kushner BJ. Long-term follow-up of regressed retinopathy of prematurity. Birth Defects Original Article Series 1988; 24: 193-9.

5 Norcia AM, Tyler CW, Piecuch R, Clyman R, Grobstein J. Development in normal and abnormal preterm human infants. $f$ Pediatr Ophthalmol Strabismus 1987; 24: infants.

6 Snir M, Nissenkorn I, Sherf I, Cohen S, Sira IB. Visual acuity, strabismus and amblyopia in preterm babies with and without retinopathy of prematurity. Ann Ophthalmol 1988; 20: 256-8.

7 Hungerford J, Stewart A, Hope P. Ocular sequelae of preterm birth and their relation to ultrasound evidence of cerebral damage. $B r \mathcal{F}$ Ophthalmol 1986; 70: 463-8.

8 Gibson NA, Fielder AR, Trounce JQ, Levene MI. Ophthalmic findings in infants of very low birthweight. Developmental Medicine and Child Neurology 1990; 32: 7-13.

9 Fielder AR, Moseley MJ, Ng YK. The immature visual system and premature birth. Br Med Bull 1988; 44: 1093-118.

10 Fielder AR, Foreman N, Moseley MJ, Robinson J. Prematurity and visual development. Infant vision. Oxford: Oxford University Press, 1990.

11 Fledelius HC. Ophthalmic changes from age of 10 to 18 years. A longitudinal study of sequels to low birth weight. II. Visual acuity. Acta Ophthalmol 1981; 59: 64-70.

12 Sebris SL, Dobson V, Hartmann EE. Assessment and prediction of visual acuity in 3- to 4-year old children born diction of visual acuity in 3- to 4-year old children
prior to term. Human Neurobiology 1984; 3: 87-92.

13 Pott JWR, Van Hof-Van Duin J. Color vision with the Farnsworth D-15 test in normal and very low birthweight children at 5 years of age. Unpublished report presented at the Third Meeting of the Child Vision Research Society, Rotterdam, 1991.

14 Abramov I, Hainline L, Lemerise E, Brown A. Changes in visual functions of children exposed as infants to prolonged illumination. $\mathcal{F} \mathrm{Am}$ Optometric Assoc 1985; 56: 614-9.

15 Moseley MJ, Fielder AR. Open letter. Light toxicity and the neonatal eye. Clin Vision Sci 1988; 3: 75-82.

16 Moseley MJ, Fielder AR. Phototherapy: an ocular hazard revisited. Arch Dis Childhood 1988; 63: 886-7.

17 Bailey IL, Lovie JE. New design principles for visual acuity letter charts. Am $\mathcal{f}$ Optom Physiol Opt 1976; 53: $740-5$.

18 Bryant KE, Gay EM, Hazell CD, Harris SP, Hollingsworth TM, Moseley MJ, et al. Visual acuity: a comparison of 3 and 6 metre test distances. Br Orthopt $\mathcal{F} 1991$; 48: 21 .

19 Pelli DG, Robson JG, Wilkins AJ. The design of a new letter chart for measuring contrast sensitivity. Clin Vision $S c i$ 1988; 2: 187-99.

20 Fitzgerald A, Mitchell J, Munns J. Pelli-Robson contrast sensitivity on 122 children aged six to twelve years. Australian Orthoptic fournal 1993; 29: 40-5.

21 Vingrys AJ, King-Smith PE. A quantitative scoring technique for panel tests of color vision. Invest Ophthalmol Vis Sci 1988; 29: 50-63. 22 Trevor-Roper PD. Lecture notes on ophthalmology: 6th ed.
Oxford: Blackwell, 1980 . 